\title{
Lianas collection from the Botanical Garden and its science-practice utilization
}

\author{
Ludmila Dorofeyeva* \\ Institute Botanic Garden Russian Academy of Sciences, Ural Branch, 620144 Ekaterinburg, Russia
}

\begin{abstract}
Collection of many years' lianas gathered in Botanical Garden, placed in south-taiga boreal area of Middle Ural. The collection bank of voluble plants is exposed of 12 genus and 17 families growing wild species of lianas originating from various areas of the Earth temperate zone and contains of more than 200 taxons. The most imposing among them is collection of genus Clematis L., which contains species of natural flora and sorts of Clematis from Russian and World selection of more than 200 taxons. Taxons are listed and analyzed by biomorphic and geographic criteria. Many years observing of collected specimens allowed getting important data about influence of climatological changes on winter hardness and procreational functions Aristolochia manschuriensis, A. macrophylla.
\end{abstract}

\section{Introduction}

Lianas are interesting biological research object and are main component of vertical plantation for they have esthetic and decorative functions, positive influence on psychoemotional human health and ability to environment-forming, enhancing microclimate of the environment. It is regret to say, that vertical plantation is rare to implement in plantation practice, which is especially actual for areas, not containing them in nature. Therefore, creation of collections and researching them in various natural and climatic conditions can motive for development of vertical plantation. Related works discuss results of liana plants introduction, some of them is for south and Europe areas of Russia [1-4]. For Asia areas this discussed in following works [5-8]. Data of cultivating several woody and grassy lianas obtained for the first time. Purpose of the research - to analyze cultivated in Middle Ural lianas collection its terms of systematic, biomorphic and geographic and to characterize their biological particulars in culture. To give a representation of research lines, which was a base for different stages of collection gathering and its.

\section{Materials, research area}

Object for research is collection of lianas from Botanical Garden of the Ural Branch of the Russian Academy of Sciences, gathered from $1990^{\text {th }}$ years. The collection placed in south-

* Corresponding author: dorofeyeva.lm@gmail.com 
taiga boreal area of Middle Ural in the Yekaterinburg city, east side of Ural Mountains. Climate is moderately continental, average year temperature is $+3^{\circ} \mathrm{C}$. Limitative factors is short vegetation. Period of active vegetation is 120 days. Cold winter temperatures. Absolute minimum $-46^{\circ}$ C. Collectible samples obtained from seeds by international exchange.

\section{Results and discussion}

Botanist garden supports systematic research for gathering lianas collection, which is constantly increasing, from $1990^{\text {th }}$ years. This leads to creation of science-practice collection of vine plants in Botanical Garden, which serves as base for research of liana biology and its introduction in conditions of Middle Ural continental climate. Collection contains growing wild species of 10 families and 12 bloodlines and 40 species, origins from different floristic areas of the Earth temperate zone, 100 hybrid species of Clematis L. bloodlines and about 50 form specimens Actinidia kolomikta, obtained with experimental way. Collection fond of lianas contains about 200 taxons. The most imposing among them is collection of family Clematis. Researched lianas form three biomorph groups by the way of attaching to pylon: Vines, hold and clamber with cirruses and leafstalks. Liana spices origins from East Asia flora (Russia Far East generally), North America, Caucasus, Europe and Mediterranean. Rare spices from the Russian Red Data Book, cultivated in collection: Aristolochia manschuriensis Kom., Dioscorea caucasica Lipsky., Dioscorea nipponica Makino [9]. This sustains to saving data about species ex situ. Next research direction was gathering of selection material for Actinidia kolomikta, which is valuable horticultural and decorative liana, suitable for Middle Ural. For form making increasing gamma irradiation with different doses was used and seedling from irradiated seed was. As a result, experimental plantation of form specimens with different characteristics of form, taste and bioactive elements was made, which allows sorting out advanced specimens. Important research direction is search of indication species, sensitive to climatological changes. There are two species Aristolochia manshuriensis и A. macrophylla, which increased its procreational functions. Fructification didn't occur during ten years of observation. Fruits of A. manshuriensis with proper seed appeared in 2020 for the first time in 25 years old and A. macrophylla in 17 years old. Early vegetation was observed in 2020 as the peak of average year temperature increased by $+5,3^{\circ} \mathrm{C}$, as previos 2018 and 2019 had these characteristics $+2,8^{\circ} \mathrm{C}$ and $+3,85^{\circ} \mathrm{C}$ respectively. Winter hardness of certain species has increased under our observation. They was roughly suitable and now became suitable for Middle Ural. Species of the collection and their biological aspects in culture are listed in Table 1. List doesn't contains sorts and hybrids of Clematis genus.

Table 1 Species and characteristics of several lianas of Botanical Garden collection

\begin{tabular}{|c|c|c|}
\hline Species & Flora* & State \\
\hline \multicolumn{3}{|c|}{ Actinidiaceae Hutch. } \\
\hline Actinidia kolomikta (RuprE.) Maxim. & EA & winterhardy, flowering, seeds \\
\hline \multicolumn{3}{|c|}{ Aristolochiaceae Juss. } \\
\hline Aristolochia macrophylla Lam. & NA & winterhardy, flowering, seeds \\
\hline
\end{tabular}




\begin{tabular}{|c|c|c|}
\hline Aristolochia manshuriensis Kom & EA & winterhardy, flowering, seeds \\
\hline \multicolumn{3}{|c|}{ Caprifoliaceae Juss. } \\
\hline Lonicera $x$ brownii & Hybrid & $\begin{array}{c}\text { winter hardiness is average, but it recovers } \\
\text { and flowering on the shoots of the current } \\
\text { year }\end{array}$ \\
\hline Lonicera caprifolium $\mathrm{L}$. & $\mathrm{E}$ & damage to annual shoots, flowering \\
\hline Lonicera prolifera (Kirchn.) Rehder & NA & winterhardy, flowering, seeds \\
\hline \multicolumn{3}{|c|}{ Dioscoreaceae R. Br. } \\
\hline Dioscorea caucasica Lipsky & Caucasus & herbaceous, flowering, seeds, \\
\hline Dioscorea nipponica Makino & EA & flowering on current shoots \\
\hline \multicolumn{3}{|c|}{ Menispermaceae Juss. } \\
\hline Menispermum canadense $\mathrm{L}$ & NA & winterhardy, flowering, seeds \\
\hline Menispermum dauricum DC. & BA & $\begin{array}{l}\text { flowering on current shoots fructify non } \\
\text { plentiful }\end{array}$ \\
\hline \multicolumn{3}{|c|}{ Ranunculaceae Juss. } \\
\hline Clematis alpina $\mathrm{L}$. (Mill.) = & $\mathrm{E}$ & winterhardy, flowering, seeds \\
\hline Clematis alpina subsp. sibirica & E, Siberia & winterhardy, flowering, seeds \\
\hline Clematis macropetala Ledeb. & $\mathrm{E}$ & winterhardy, flowering, seeds \\
\hline Clematis ochotensis Pall. & EA & winterhardy, flowering, seeds \\
\hline Clematis crispa $\mathrm{L}$ & NA & flowering on current increment, seeds \\
\hline Clematis campaniflora Brot. & $\mathrm{E}$ & flowering on current increment, seeds \\
\hline Clematis flammula $\mathrm{L}$. & $\mathrm{E}$ & flowering on current increment, seeds \\
\hline Clematis glauca Willd. & EA & flowering on last year's shoots \\
\hline
\end{tabular}




\begin{tabular}{|c|c|c|}
\hline Clematis fusca Turcz. & EA & flowering on current increment, seeds \\
\hline Clematis ianthina Koenhe & EA & flowering on current increment, seeds \\
\hline Clematis heracleifolia DC & EA & late flowering on current increment \\
\hline C. intricate Bunge & NA & late flowering on current increment \\
\hline C. ligusticifolia Nutt. & NA & winterhardy, flowering \\
\hline C. manschurica Rupr. & & flowering on current increment, seeds \\
\hline C. serratifolia Rehd. & EA & late flowering on current increment \\
\hline C. tangutica (Maxim.) Korsh. & MA & flowering on last years and current shoots \\
\hline C. terniflora DC. & Japan & $\begin{array}{c}\text { non winterhardy, require cover, only budding } \\
\text { was observed }\end{array}$ \\
\hline$C$ virginiana $\mathrm{L}$. & NA & flowering on current increment \\
\hline C. viticella $\mathrm{L}$. & $\mathrm{E}$ & flowering on current increment \\
\hline \multicolumn{3}{|c|}{ Schisandraceae Blume } \\
\hline Schisandra chinensis (Turcz.) Baill. & EA & winterhardy, flowering. seeds \\
\hline \multicolumn{3}{|c|}{ Vitaceae Juss. } \\
\hline Ampelopsis aconitifolia Bge. & EA & damaging, recovering \\
\hline $\begin{array}{l}\text { Parthenocissus inserta } \\
\text { (Kern.) Fritsch }\end{array}$ & SA & winterhardy, flowering, seeds \\
\hline $\begin{array}{c}\text { Parthenocissus } \\
\text { quinquefolia (L.) Planch. }\end{array}$ & NA & winterhardy, flowering, seeds \\
\hline Vitis acerifolia Raf. & NA & damaging, recovering \\
\hline Vitis amurensis Rupr. & EA & winterhardy, flowering, seeds \\
\hline Vitis berlandieri Planch. & NA & damaging, recovering \\
\hline
\end{tabular}




\begin{tabular}{|c|c|c|}
\hline Vitis riparia Michx. & NA & damaging, recovering \\
\hline Vitis rupestris Scheele & NA & damaging, recovering \\
\hline Vitis vulpine L. & NA & damaging, recovering \\
\hline
\end{tabular}

* Notice: EA - East Asia, NA - Nord America, E-Europe, MA- Middle Asia

\section{Conclusion}

Introduced species of Botanical Garden Ural Branch RAN collection are valuable science objects for theoretical and practical researches as well as beautiful decorative leaf and flourish lianas and some of them - fructify and medicinal plants. They are suitable in plantation and economy of Middle Ural. Observed bines damaging isn't restriction for their utilizing in planting practice. Many years of research showed, that, despite the significant damaging if several species of lianas in winter phase, they successfully recovering after the winter, flourish and fructify on beans from current year. These are some of the species Clematis, Lonicera caprifolium, L. x brownii, Menispermum dauricum, Vitis.

The work was performed as part of the State Assignment for the Botanical Garden of the Ural Branch of the Russian Academy of Sciences

\section{References}

1. N. G. Bakhnovskaya, Wood vines in Moldova (Chisinau, Shtiintsa, 1987)

2. H. B. Zubkova, Clematis in the Nikitsky Botanical Garden, the bill of the state Nikitsky Botanical Gardenб, 99 (2009)

3. T. P. Chebannaya, Some results of the introduction of the genus Clematis in the Stavropol Botanical Garden IM. V.V. Skripchinsky, Bulletin APC Stavropol, 23 (2016)

4. T. M. Zhavkina, To the features of the collection of liana plants in botanical gardens, Samara State University Bulletin, 8 (58) (2007)

5. T. N. Vstovskaya, I. Yu. Koropachinskij, Woody plants of the Central Siberian Botanical Garden (Novosibirsk, Geo, 2005)

6. N. I. Denisov, Woody Vines of the Russian Far East (Vladivostok, Dalnauka, 2003)

7. N. P. Lapteva, Collection of woody lianas in Central Siberian Botanical Garden, SB RAS, Vestnik Ir GSA 44 (2011)

8. L. A. Klementyeva, Lianas as an additional and limited assortment for gardening in the Altai Territory, Subtropical and ornamental gardening, 71 (2019)

9. The Russian Federation Red Book (plants and fungi) (Moscow: KMK, 2008) 